\title{
ESTUDO DAS RELAÇÕES DOS ATORES SOCIAIS NO COMPLEXO INDUSTRIAL FLORESTAL DE MINAS GERAIS ${ }^{1}$
}

\author{
Rosa Maria Miranda Armond Carvalho², Sebastião Renato Valverde ${ }^{3}$, Laércio Antônio Gonçalves \\ Jacovine $^{3}$, Afonso Augusto Teixeira de Freitas de Carvalho Lima ${ }^{4}$, Lourival Marin Mendes ${ }^{5}$, José Luiz \\ Pereira de Rezende ${ }^{5}$ e Rommel Noce ${ }^{2}$
}

\begin{abstract}
RESUMO - O objetivo deste estudo foi conhecer as interações entre os diferentes atores sociais relacionados às empresas do complexo industrial florestal de Minas Gerais. Tendo em vista tratar os dados obtidos, utilizouse a adaptação da escala Likert como mecanismo de medida, tornando possível aferir o grau de concordância e importância atribuídas pelos entrevistados diante das afirmativas descritas no questionário aplicado. A relação com o governo, sociedade, clientes, fornecedores e concorrentes é considerada importante, sendo a busca por informações prática generalizada. A carga tributária, a má qualidade da rede viária e o apoio insuficiente destacaram-se como obstáculos ao desenvolvimento da atividade produtiva.
\end{abstract}

Palavras-chave: Complexo florestal e industrial, interação dos atores sociais e administração florestal.

\section{STUDY OF THE RELATIONSHIPS OF SOCIAL ACTORS IN THE FOREST INDUSTRIAL COMPLEX OF MINAS GERAIS}

\begin{abstract}
The objective of this study was to understand the interactions among the different social actors involved in the forest industrial complex companies. To work with the data obtained, an adaptation of the Likert scale as a measurement mechanism was used, allowing checking the degree of agreement and the importance attributed by the interviewees in relation to the statements described in the questionnaire. The relation with the government, society, customers, suppliers and competitors is considered important, with the search for information being a widespread practice. Government taxes, the bad quality of the road system and insufficient support were the major obstacles to the development of the productive activity.
\end{abstract}

Keywords: Industrial and forest complex, social actors' interaction and forest administration.

\section{INTRODUÇÃO}

Ao examinar diferentes estudos do setor florestal brasileiro, pôde-se observar sua importância para o país. Tal fato pode ser comprovado através da significativa participação do setor nos indicadores socioeconômicos, como no Produto Interno Bruto (PIB), na geração de empregos, na arrecadação de impostos, na remuneração do trabalho e na formação de divisas via exportações (VALVERDE et al., 2003).
A cobertura florestal do território brasileiro, associada às excelentes condições edafoclimáticas para a silvicultura, confere ao país grandes vantagens comparativas para a atividade florestal (CARVALHO et al., 2003).

Noce et al. (2003) ressaltaram que as exportações de produtos florestais estão crescendo significativamente, e o Brasil já se mostra expressivo no comércio internacional de compensados tropicais, chapas de fibra, celulose de eucalipto e de papéis para imprimir e escrever.

\footnotetext{
${ }^{1}$ Recebido em 14.09.2007 e aceito para publicação em 06.03.2009.

${ }^{2}$ Programa de Pós-Graduação em Ciência Florestal da Universidade Federal de Viçosa (UFV). E-mail: <rosamaria@ homenet.com.br> e <rommelnoce@yahoo.com.br>.

${ }^{3}$ Departamento de Engenharia Florestal da UFV. E-mail: <valverde@ufv.br> e <jacovine@ufv.br>.

${ }^{4}$ Departamento de Administração da UFV. E-mail: <afonsoli@ufv.br> e <jlprezen@ufla.br>.

${ }^{5}$ Departamento de Ciências Florestais da Universidade Federal de Lavras (UFLA). E-mail: <lourival@ufla.br>.
} 
Atualmente, o setor florestal colabora para o crescimento da economia brasileira, proporcionando benefícios sociais e ambientais, por intermédio da exploração sustentável dos recursos renováveis florestais (ABIMCI, 2003). Nesse contexto, diversas empresas vêm apresentando renovado interesse pela atividade florestal (NOCE et al., 2005).

As empresas brasileiras, independentemente do setor de atuação, tamanho ou estrutura, estão enfrentando maiores desafios, entre eles a globalização da economia, os ambientes externo e interno gradativamente mais dinâmicos, clientes exigentes e rápidas mudanças nos produtos e processos em função de avanços tecnológicos. Essas empresas devem apresentar alto grau de qualidade, diversidade, produtividade, agilidade e flexibilidade, para serem efetivas e cumprir seu papel social, como agentes de desenvolvimento da região onde estão inseridas.

O complexo florestal industrial é representativo e possui grande potencial para colaborar com o desenvolvimento do Estado de Minas Gerais. Conforme o Instituto de Desenvolvimento Industrial de Minas Gerais - Indi (2006), especificamente no Estado, o setor florestal merece destaque, pois mais da metade das plantações de eucalipto no Brasil $(52,6 \%)$ está localizada em Minas Gerais. Em relação ao pinus, a ocupação de área plantada é de 8,5\% (menos expressiva), porém com boas possibilidades de aproveitamento.

Segundo Assis (2003), a indústria de base florestal participa com 7\% do PIB mineiro, gera 565.328 empregos diretos e indiretos, arrecada R \$ 354 milhões em impostos e agrega 3.762 mil reais em divisas de exportação. Entretanto, apesar de sua importância no contexto brasileiro, não se encontraram pesquisas visando à construção de uma visão abrangente, particularmente, sobre o ambiente organizacional.

Ambiente organizacional é tudo aquilo que envolve externamente uma organização, ou seja, é o que está além de suas fronteiras. As organizações vivem e operam em outras em cooperação, competição ou confronto. $\mathrm{O}$ ambiente pode ser desdobrado em ambientes específico e geral. O específico refere-se ao mais próximo e imediato de cada organização e o geral, ao meio mais amplo que envolve toda a sociedade, as nações, organizações, empresas e comunidades (CHIAVENATO, 1999).

O ambiente é uma fonte de recursos e oportunidades para a organização extrair os insumos necessários ao seu funcionamento e subsistência, mas é também, uma fonte de restrições, limitações, coações, problemas, ameaças e contingências para a sua sobrevivência (PORTER, 1992). Isso torna difícil definir, exatamente, onde termina um contexto ambiental e o outro (ANSOFF, 1990).

O ambiente oferece recursos, clientes e oportunidades, mas, também, concorrentes, agências reguladoras, problemas e desafios à organização. As importantes e rápidas transformações vivenciadas pelo Complexo Florestal e Industrial exigem que se busquem mecanismos para os setores público e privado anteciparem os desafios presentes e futuros e alinharem sustentabilidade com produção.

Assim, os objetivos deste trabalho foram levantar e descrever aspectos relativos a governo, sociedade, meio ambiente, clientes, fornecedores, concorrentes e entrantes potenciais para o setor florestal industrial no Estado de Minas Gerais.

\section{MATERIAL E MÉTODOS}

\subsection{População e amostra}

O universo desta pesquisa foram empresas da cadeia produtiva da madeira de Minas Gerais. Em razão das particularidades do universo da pesquisa, utilizou-se uma amostra privilegiando empresas com atributos que o pesquisador deseja conhecer; logo, tal amostra é do tipo intencional ou, por julgamento, nãoprobabilística.

A escolha das unidades de análise visou contemplar a diversidade das empresas de base florestal. Devido à extensão do setor florestal, enfocou-se apenas o segmento madeireiro, o que foi feito com o apoio de listagens da Sociedade de Investigações Florestais (SIF), da Associação Mineira de Silvicultura (AMS) e do Sindicato da Indústria do Ferro no Estado de Minas Gerais (SINDIFER), além de 36 especialistas. Estes indicaram as empresas consideradas representativas do setor florestal mineiro, segundo o critério descrito por Polzl et al. (2003) que segmenta a cadeia produtiva da madeira em três grandes cadeias, em função das distinções na utilização da madeira bruta: madeira industrial, energia e processamento mecânico.

Procedeu-se ao cruzamento desses dados, o que gerou uma lista de 28 empresas, sendo duas de madeira industrial, 22 de energia e quatro de processamento mecânico. 
A seguir, buscou-se selecionar as empresas, de cada cadeia produtiva de acordo com seu tamanho, localização etc. Assim, obteve-se uma amostra composta de 16 empresas, sendo duas de madeira industrial, 12 de energia e duas de processamento mecânico.

Das 16 empresas visitadas, 11 responderam (retorno porcentual de $68,75 \%$ ), sendo duas da madeira industrial, sete da energia e duas do processamento mecânico.

O respondente teria que ter conhecimento global da empresa para qualidade dos dados do instrumento de coleta proposto. $\mathrm{O}$ grupo selecionado foi composto por seis gerentes, três superintendentes e dois diretores ocupando o cargo por mais de três anos e na função a mais de dois anos.

\subsection{Instrumentos de coleta de dados}

A coleta de dados foi realizada de março a dezembro de 2004 com o uso de fontes primárias e secundárias. Os dados primários foram coletados por meio de pesquisa de campo. Os dados secundários foram obtidos através de levantamento bibliográfico.

O instrumento de coleta de dados foi composto por questionário com perguntas relativas ao perfil da empresa e às suas interações com o governo, sociedade, meio ambiente, clientes, fornecedores, concorrentes e entrantes potenciais. Continha afirmativas, às quais o respondente associou respostas relativas ao seu grau de concordância com elas. As respostas às afirmações variaram com a escala de Likert: (5) - Concordo Totalmente, (4) - Concordo, (3) - Concordo Parcialmente, (2) - Discordo e (1) - Discordo Totalmente.

\subsection{Tratamento e análise de dados}

Tendo em vista tratar os dados obtidos através de questionário estruturado, utilizou-se a adaptação da escala Likert, descrita por Oliveira (2005), como mecanismo de medida, tornando possível aferir o grau de concordância e importância atribuídas pelos entrevistados diante das afirmativas descritas no questionário. Foi utilizado como ferramenta de apoio para tabulação dos dados o Statistic Package for Social Science (SPSS) e o Microsoft Excel. Em seguida, gerouse um valor ponderado, indicando a posição do grupo de entrevistados em relação a cada afirmação. Para tanto, foi realizado o somatório do produto das frequências absolutas pelos respectivos valores associados a cada nível, sendo o valor obtido dividido pelo produto entre a frequência total e o valor associado à máxima concordância (5). Por fim, multiplicou-se esse resultado por 10 , obtendo-se um valor ponderado em uma escala de 0 a 10.

O valor ponderado 6 foi considerado como balizador, pois se hipoteticamente todos os respondentes adotassem uma posição central diante das afirmações, escolhendo o item "concordo parcialmente", este seria o valor ponderado obtido. Assim, os resultados acima de 6 foram considerados como posição de concordância e os abaixo desse valor, como de discordância.

\section{RESULTADOS E DISCUSSÃO}

As indústrias de base florestal que participaram do estudo eram organizações de médio e grande portes com mais de 10 anos de existência, em sua maioria optantes pela tipologia jurídica de sociedade limitada. Uma está localizada dentro de um distrito industrial, uma em um polo industrial e uma na área da Superintendência do Desenvolvimento do Nordeste (SUDENE). Vale destacar que a maioria das empresas teve sua origem na separação da área florestal de outra empresa, que optou, em algum momento, pelo registro de uma nova pessoa jurídica por questões estratégicas.

Na Tabela 1, podem-se verificados a atividade econômica predominante e o setor de atividade das empresas. No que diz respeito à classificação de clientes, a grande maioria tem como principal cliente empresas privadas de porte grande, o que pode ser explicado tanto pela origem das empresas, quanto pela sua localização na cadeia produtiva (Tabela 2 ).

\subsection{Aspectos relativos a clientes, fornecedores, concorrentes e entrantes potenciais}

Os aspectos relativos à relação com clientes, fornecedores, concorrentes e entrantes potenciais são de extrema importância para as empresas. Os clientes são pessoas e organizações no ambiente que adquirem bens e serviços das organizações, sendo determinantes para seu sucesso.

O grau de concordância aferido sobre os aspectos relativos à relação com clientes indica que tais relações encontram-se bem sedimentadas nas empresas estudadas (Tabela 3), o que pode ser atribuído ao fato de a maioria das empresas ter como principal cliente empresas consumidoras de matéria-prima de porte grande.

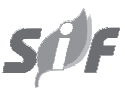

R. Árvore, Viçosa-MG, v.33, n.2, p.359-366, 2009 
Tabela 1 - Atividade econômica predominante e setor de atividade das empresas

Table 1 - Predominant economic activity and activity sector of the companies

\begin{tabular}{|c|c|c|c|}
\hline Cadeia Produtiva & $\mathrm{N}^{\circ}$ de Empresas & Atividade Econômica Predominante & Setor de Atividade \\
\hline Madeira industrial & 2 & Integrada (floresta + indústria) & $\begin{array}{c}\text { Chapas de madeira reconstituída } \\
\text { Celulose de mercado }\end{array}$ \\
\hline Energia & 2 & Plantação de florestas & Florestal \\
\hline & 5 & Integrada (floresta + indústria) & Siderurgia \\
\hline Processamento & 2 & Integrada (floresta + indústria) & Serraria \\
\hline mecânico & & & $\begin{array}{l}\text { Processamento de madeira de } \\
\text { eucalipto para uso múltiplo }\end{array}$ \\
\hline
\end{tabular}

Tabela 2 - Classificação do cliente principal quanto ao porte e à categoria

Table 2 - Main customer's classification by load and category

\begin{tabular}{|c|c|c|c|c|}
\hline Cadeia Produtiva & $\mathrm{N}^{\circ}$ de Empresas & Porte & Categoria & Destino das Vendas \\
\hline \multirow[t]{2}{*}{ Madeira industrial } & 1 & $\begin{array}{l}\text { Empresa privada } \\
\text { de grande porte }\end{array}$ & $\begin{array}{l}\text { Consumidor de } \\
\text { matéria-prima }\end{array}$ & Próprio estado \\
\hline & 1 & $\begin{array}{l}\text { Empresa privada } \\
\text { de médio porte }\end{array}$ & $\begin{array}{l}\text { Consumidor de } \\
\text { matéria-prima }\end{array}$ & $\begin{array}{c}\text { Maior parte para } \\
\text { o exterior }\end{array}$ \\
\hline \multirow[t]{3}{*}{ Energia } & 1 & $\begin{array}{l}\text { Empresa privada } \\
\text { de grande porte }\end{array}$ & $\begin{array}{l}\text { Consumidor de } \\
\text { matéria-prima }\end{array}$ & $\begin{array}{c}\text { Maior parte para } \\
\text { o exterior }\end{array}$ \\
\hline & 5 & $\begin{array}{l}\text { Empresa privada } \\
\text { de grande porte }\end{array}$ & $\begin{array}{l}\text { Consumidor de } \\
\text { matéria-prima }\end{array}$ & $\begin{array}{l}\text { Maior parte para } \\
\text { o próprio estado }\end{array}$ \\
\hline & 1 & $\begin{array}{l}\text { Empresa privada } \\
\text { de grande porte }\end{array}$ & Distribuidor & $\begin{array}{l}\text { Maior parte para } \\
\text { o próprio estado }\end{array}$ \\
\hline \multirow[t]{2}{*}{ Processamento mecânico } & 1 & $\begin{array}{l}\text { Empresa privada } \\
\text { de porte grande } \\
\text { Pessoa física }\end{array}$ & $\begin{array}{l}\text { Consumidor } \\
\text { final }\end{array}$ & $\begin{array}{l}\text { Maior parte para } \\
\text { o próprio estado }\end{array}$ \\
\hline & 1 & $\begin{array}{l}\text { Empresa privada } \\
\text { de porte grande }\end{array}$ & $\begin{array}{l}\text { Consumidor de } \\
\text { matéria-prima } \\
\text { Distribuidor }\end{array}$ & $\begin{array}{c}\text { Maior parte para } \\
\text { o exterior }\end{array}$ \\
\hline
\end{tabular}

Tabela 3 - Aspectos relativos a clientes, fornecedores, concorrentes e entrantes potenciais nas empresas de Madeira Industrial (MI), Energia (E) e Processamento Mecânico (PM)

Table 3 - Aspects related to customers, suppliers, competitors and potential incomings in Industrial Wood (IW), Energy (E) and Mechanical Processing (MP) companies

\begin{tabular}{|c|c|c|c|}
\hline \multirow[t]{2}{*}{ Clientes } & \multicolumn{3}{|c|}{ Cadeia Produtiva } \\
\hline & MI & $\mathrm{E}$ & PM \\
\hline A empresa busca sistematicamente identificar as necessidades dos clientes & 7,00 & 9,14 & 8,00 \\
\hline A empresa possui alto grau de retenção de clientes & 10,00 & 9,14 & 8,00 \\
\hline $\begin{array}{l}\text { Os clientes da empresa são informados sistematicamente sobre os produtos oferecidos } \\
\text { Fornecedores }\end{array}$ & 10,00 & 8,85 & 8,00 \\
\hline A empresa possui políticas de desenvolvimento de fornecedores & 8,00 & 6,85 & 7,00 \\
\hline A empresa troca informações com os fornecedores & 8,00 & 8,0 & 7,00 \\
\hline A empresa possui sistema para a avaliação de seus fornecedores & 8,00 & 7,42 & 6,00 \\
\hline A empresa exige que seus fornecedores sejam certificados & 5,00 & 4,85 & 4,00 \\
\hline A empresa tem habilidade na gestão de parcerias com outras empresas & 8,00 & 8,00 & 7,00 \\
\hline $\begin{array}{l}\text { A decisão de realizar alianças está, frequentemente, relacionada a decisões estratégicas } \\
\text { e aprendizado importantes }\end{array}$ & 6,00 & 6,35 & 7,00 \\
\hline Concorrentes & MI & $\mathrm{E}$ & PM \\
\hline A empresa adota processos de vigilância concorrencial & 8,00 & 4,85 & 5,00 \\
\hline $\begin{array}{l}\text { Existe alto nível de crescimento do mercado interno para os } \\
\text { produtos/serviços oferecidos pela empresa }\end{array}$ & 8,00 & 9,14 & 5,00 \\
\hline $\begin{array}{l}\text { Existe alto nível de crescimento do mercado externo para os } \\
\text { produtos/serviços oferecidos pela empresa }\end{array}$ & 9,00 & 7,14 & 7,00 \\
\hline A concorrência possui alto grau de inovação tecnológica & 7,00 & 6,00 & 5,00 \\
\hline A concorrência possui alto grau de agressividade & 7,00 & 6,00 & 6,00 \\
\hline Entrantes & MI & $\mathrm{E}$ & $\mathrm{PM}$ \\
\hline É necessário alto investimento para a entrada no negócio & 10,0 & 9,42 & 7,00 \\
\hline Existem muitas barreiras para a entrada de novas empresas no mercado & 10,0 & 7,42 & 6,00 \\
\hline Existe facilidade de acesso de terceiros às informações de mercado e tecnologias & 9,00 & 8,57 & 8,00 \\
\hline Existe facilidade de acesso de terceiros aos mercados e parceiros da empresa & 9,00 & 8,28 & 7,00 \\
\hline
\end{tabular}

* $>$ 6,0 posição de concordância e $<6,0$ posição de discordância.

R. Árvore, Viçosa-MG, v.33, n.2, p.359-366, 2009 
Todas as empresas da madeira industrial e do processamento mecânico e duas da energia afirmaram buscar informações sobre clientes e mercado, continuamente. As cinco empresas restantes relataram fazê-lo regularmente.

Duas empresas da madeira industrial, sete da energia e uma do processamento mecânico afirmaram trocar idéias e informações com empresas clientes. As ações conjuntas de "marketing" eram desenvolvidas por apenas uma empresa do processamento mecânico.

Os fornecedores são elementos que proporcionam insumos na forma de recursos, energia, serviços e informações à empresa.

O grau de concordância aferido evidenciou que as relações com fornecedores se encontravam, de maneira geral, bem desenvolvidas, mas existe unanimidade quanto à não-exigência de certificação de seus fornecedores (Tabela 3). Isso pode ser preocupante, pois a certificação é uma declaração de que o fornecedor atende um conjunto de parâmetros de desempenho, como o fornecimento na quantidade exata, no tempo determinado e na qualidade requerida.

Uma empresa da madeira industrial, duas do processamento mecânico e três da energia afirmaram buscar informações sobre fornecedores regularmente, e as cinco restantes, quatro da energia e uma do processamento mecânico, afirmaram fazê-lo continuamente.

Duas empresas da madeira industrial, duas do processamento mecânico e quatro da energia afirmaram trocar idéias e informações com empresas fornecedoras. Duas empresas da energia e uma do processamento mecânico relataram utilizar treinamento conjunto de funcionários.

O grau de concordância aferido nas empresas da madeira industrial, referente à relação com concorrentes, é mais alto que os da energia, que por sua vez também é maior que o aferido nas empresas do processamento mecânico (Tabela 3), o que pode ser atribuído à disparidade no número de concorrentes.

As duas empresas da madeira industrial não possuíam concorrentes no Estado, e nacionalmente havia poucos (uma delas possuía seis concorrentes de grande porte e a outra, três de médio porte e quatro de grande porte).

As empresas da energia e do processamento mecânico afirmaram ter vários concorrentes de diferentes portes, o que é coerente com a localização na cadeia produtiva.
As empresas da madeira industrial, duas da energia e uma do processamento mecânico, afirmaram buscar regularmente informações relativas à concorrência. Três empresas da energia e uma do processamento mecânico afirmaram fazê-lo regularmente e duas da energia o faziam esporadicamente.

Todas as empresas afirmaram trocar idéias e informações com as empresas concorrentes. Uma empresa de energia relatou fazer ensaios conjuntos para desenvolvimento e melhoria de insumos, produtos e processos. Uma empresa do processamento mecânico afirmou utilizar essa prática para o treinamento de funcionários.

Nos aspectos relativos à relação com entrantes, observou-se a existência de barreiras para novos concorrentes, apesar da facilidade de acesso às informações de mercado e tecnologias, bem como aos mercados e parceiros da empresa. O grau de concordância aferido nas empresas da madeira industrial, referente a entrantes, é mais alto que os da energia, que por sua vez também é maior que o aferido nas empresas do processamento mecânico (Tabela 3 ).

As informações relativas ao uso e oferta de tecnologias são buscadas regularmente por uma empresa da madeira industrial e três da energia. Seis empresas, uma da madeira industrial, quatro da energia e uma do processamento mecânico, o fazem continuamente, e apenas uma empresa do processamento mecânico só busca essas informações esporadicamente.

Uma empresa da madeira industrial e três da energia e uma do processamento mecânico fazem esporadicamente busca de informações sobre novos produtos. Uma empresa da energia as buscava regularmente, e uma da madeira industrial, três da energia e uma do processamento mecânico a realizavam continuamente.

\subsection{Aspectos relativos a governo, sociedade e meio ambiente}

As empresas afirmaram possuir comportamento adequado com relação às normas técnicas exigidas e sugeridas para o seu setor de atividade.

No que diz respeito à atuação do governo, o baixo grau de concordância aferido demonstrou a insatisfação das empresas pesquisadas no que diz respeito a programas de apoio à exportação e subsídios, ao fornecimento de infraestrutura de transporte e comunicação e ao apoio a institutos tecnológicos setoriais e centros especializados para a indústria (Tabela 4).

R. Árvore, Viçosa-MG, v.33, n.2, p.359-366, 2009 
Duas empresas da madeira industrial, seis da energia e uma do processamento mecânico afirmaram trocar idéias e informações com os governos locais. Entretanto, as duas empresas restantes afirmaram não fazê-lo.

As empresas buscavam colaborar com o desenvolvimento social. Entretanto, o grau de importância da comunicação com a comunidade local era mais baixo, o que demonstra ser este o ponto mais fraco relacionado a tal aspecto (Tabela 4).

As empresas afirmaram possuir atuação bastante pertinente no que diz respeito à questão ambiental. Vale ressaltar que o grau de concordância aferido sobre essa questão foi mais baixo nas empresas do processamento mecânico (Tabela 4).

Duas empresas da madeira industrial, seis da energia e uma do processamento mecânico afirmaram trocar idéias e informações com os Institutos de Ensino e Pesquisa. Três empresas da energia e uma do processamento mecânico relataram desenvolver ensaios para desenvolvimento e melhoria de insumos, produtos e processos em parceria com essas instituições, e apenas uma empresa da energia as utilizava no treinamento de funcionários.
Duas empresas da madeira industrial, cinco da energia e uma do processamento mecânico afirmaram trocar idéias e informações com os institutos de apoio às empresas. Duas empresas da energia desenvolviam ações conjuntas de "marketing". Apenas uma empresa da energia afirmou não estabelecer relações com essas instituições.

A participação das empresas em associações foi significativa, o que pode ser entendido como ponto positivo para o setor (Tabela 5).

A participação das empresas em programas sociais é forte, uma vez que apenas três empresas afirmaram não ter esse tipo de atuação (Tabela 5).

Todas as empresas relataram a carga tributária elevada e a qualidade das estradas federais como problema, o que é condizente com o momento que se vivencia atualmente no país (Tabela 5). A qualidade da malha viária está diretamente relacionada com os custos da atividade florestal (ANGELO et al., 1998).

Todas as empresas da energia relataram apoio governamental insuficiente. Quatro empresas da energia e uma do processamento mecânico incluíram a legislação e a atuação do IEF na lista de principais problemas.

Tabela 4 - Relação com o governo, sociedade e ambiente nas em empresas de Madeira Industrial (MI), Energia (E) e Processamento Mecânico (PM)

Table 4-Relationship with the government, society and the environment in the Industrial Wood (IW), Energy (E) and Mechanical Processing (MP) companies

\begin{tabular}{|c|c|c|c|}
\hline \multirow[t]{2}{*}{ Clientes } & \multicolumn{3}{|c|}{ Cadeia Produtiva } \\
\hline & MI & $\mathrm{E}$ & $\mathrm{PM}$ \\
\hline $\begin{array}{l}\text { A empresa possui comportamento adequado com relação às normas técnicas } \\
\text { exigidas e sugeridas para o seu setor de atividade }\end{array}$ & 9,00 & 9,42 & 8,00 \\
\hline $\begin{array}{l}\text { A atuação do governo em relação a programas de apoio à exportação } \\
\text { e subsídios para a indústria é satisfatória }\end{array}$ & 4,00 & 4,57 & 5,00 \\
\hline $\begin{array}{l}\text { A atuação do governo em relação ao fornecimento de infraestutura de transporte } \\
\text { e comunicação para a indústria é satisfatória }\end{array}$ & 3,00 & 5,14 & 5,00 \\
\hline $\begin{array}{l}\text { A atuação do governo em relação ao apoio a institutos tecnológicos setoriais } \\
\text { e centros especializados para a indústria é satisfatória }\end{array}$ & 5,00 & 5,42 & 5,00 \\
\hline Sociedade & MI & $\mathrm{E}$ & PM \\
\hline A empresa participa de instituições de representação empresarial & 10,0 & 8,00 & 8,00 \\
\hline A empresa possui políticas e práticas que dizem respeito às questões sociais & 8,00 & 9,43 & 7,00 \\
\hline A empresa está envolvida em questões de interesse da comunidade onde está inserida & 8,00 & 9,42 & 7,00 \\
\hline A empresa possui políticas e práticas com relação ao respeito aos direitos do consumidor & 9,00 & 8,57 & 8,00 \\
\hline A empresa possui boa imagem perante a comunidade & 9,00 & 8,57 & 8,00 \\
\hline $\begin{array}{l}\text { A empresa possui canal de comunicação com a comunidade local em } \\
\text { relação às questões sociais }\end{array}$ & 6,00 & 6,00 & 6,00 \\
\hline $\begin{array}{c}\text { A empresa contribui significativamente com a melhoria da qualidade de vida da comunidade } \\
\text { Ambiente }\end{array}$ & $\begin{array}{l}9,00 \\
\mathrm{MI}\end{array}$ & $\begin{array}{c}9,42 \\
\mathrm{E}\end{array}$ & $\begin{array}{l}7,00 \\
\mathrm{PM}\end{array}$ \\
\hline A empresa possui políticas e práticas que dizem respeito à questão ambiental & 10,0 & 9,14 & 8,00 \\
\hline Existe alto grau de exigência do mercado em relação à certificação ambiental & 9,00 & 9,14 & 7,00 \\
\hline A empresa atua em projetos de recuperação e preservação dos recursos naturais & 9,00 & 9,42 & 6,00 \\
\hline $\begin{array}{l}\text { A empresa possui canal de comunicação com a comunidade e com os acionistas sobre } \\
\text { sua atuação nas questões ambientais }\end{array}$ & 9,00 & 8,00 & 6,00 \\
\hline
\end{tabular}

* > 6,0 posição de concordância e $<6,0$ posição de discordância. 
Tabela 5 - Serviços de apoio institucional, participação em associações, programas sociais e principais problemas enfrentados pelas nas empresas de Madeira Industrial (MI), Energia (E) e Processamento Mecânico (PM)

Table 5 - Institutional support services, association participation, social programs and major problems faced by the Industrial Wood (IW), Energy (E) and Mechanical Processing (MP) companies

\begin{tabular}{|c|c|c|c|c|}
\hline \multirow[t]{2}{*}{ Serviço de Apoio Institucional } & \multicolumn{3}{|c|}{ Cadeia Produtiva } & \multirow{2}{*}{$\begin{array}{c}\text { Total } \\
\text { de Empresas }\end{array}$} \\
\hline & MI & $\mathrm{E}$ & $\mathrm{PM}$ & \\
\hline SENAC/SENAI & 1 & 2 & & 3 \\
\hline SEBRAE & 1 & 2 & & 3 \\
\hline Sindicatos & 1 & 4 & & 5 \\
\hline SESC/SESI & & 1 & 1 & 1 \\
\hline Universidades & 1 & 1 & & 2 \\
\hline SENAR & & 2 & 1 & 1 \\
\hline \multicolumn{5}{|l|}{ Participação em Associações } \\
\hline SIF & 2 & 4 & 1 & 7 \\
\hline AMS & 2 & 5 & 1 & 8 \\
\hline IPEF & 1 & 3 & & 4 \\
\hline SBS & 1 & 3 & & 4 \\
\hline ABRAF & 1 & & & 1 \\
\hline ASIFLOR & & 1 & & 1 \\
\hline ABPM & & & 1 & 1 \\
\hline \multicolumn{5}{|l|}{ Participação em Programas } \\
\hline Parceria agrícola & 1 & 1 & & 2 \\
\hline Parceria apícola & 1 & 1 & & 2 \\
\hline $\begin{array}{l}\text { Projetos sociais em parceria com prefeituras, } \\
\text { sindicatos e outras entidades das comunidades }\end{array}$ & 2 & & & 2 \\
\hline Incentivo à cultura & & 1 & & 1 \\
\hline Programa de combate às drogas & & 1 & & 1 \\
\hline Cursos de: educação ambiental, economia no lar, jovem cidadão & & 1 & & 1 \\
\hline Conservação de vias & & 1 & & 1 \\
\hline Doações diversas & & 5 & 1 & 5 \\
\hline Desenvolvimento de empreendimentos empresariais & & 1 & & 1 \\
\hline Não participam & & 2 & 1 & 3 \\
\hline \multicolumn{5}{|l|}{ Principais Problemas Enfrentados } \\
\hline Carga tributária elevada & 2 & 7 & 2 & 11 \\
\hline Qualidade das estradas federais & 2 & 7 & 2 & 11 \\
\hline Concorrência intensificada & 1 & 1 & & 2 \\
\hline Falta de mão-de-obra qualificada & & 2 & 1 & 3 \\
\hline Rotatividade da mão-de-obra & & 1 & & 1 \\
\hline $\begin{array}{l}\text { Apoio governamental insuficiente (relativo ao desenvolvimento } \\
\text { tecnológico, incentivos fiscais, acesso ao crédito etc.) }\end{array}$ & & 7 & & 7 \\
\hline Legislação & 4 & 1 & 5 & \\
\hline Atuação do IEF & & 4 & 1 & 5 \\
\hline $\begin{array}{l}\text { Matérias-primas e insumos inadequados } \\
\text { (florestas em quantidade escassa) }\end{array}$ & & & 1 & 1 \\
\hline Falta de capital para investimentos & & & 1 & 1 \\
\hline
\end{tabular}

\section{CONCLUSÕES}

- A relação com os diversos atores sociais, fornecedores, clientes, concorrentes e entrantes potenciais foi considerada importante. Apesar da facilidade de acesso a informações, tecnologia, mercados e parceiros, existem barreiras de entrada para novos participantes, pois o capital inicial necessário foi considerado alto.
* A busca por informações é prática generalizada, e há uma busca contínua por informações do mercado, por meio da troca de informações sobre clientes, fornecedores, concorrência, tecnologia e produtos.

* O acesso a informação interna e incentivado, não ocorrendo o mesmo com o fluxo de informação para o ambiente externo. Embora haja empenho em gerar

R. Árvore, Viçosa-MG, v.33, n.2, p.359-366, 2009 
resultados sobre a atividade produtiva, estes não são amplamente divulgados.

* A interação entre os concorrentes diminui gradativamente da cadeia da Madeira Industrial para a de Energia e para a de Processamento Mecânico, apesar de todos trocarem informações.

* Há intercâmbio com instituições de ensino e pesquisa, assim como participação efetiva em associações e em programas sociais.

* A carga tributária, a má qualidade da rede viária e o apoio insuficiente do Estado são apontados como os principais obstáculos ao desenvolvimento da atividade produtiva. Observou-se insatisfação das empresas da energia com a ação governamental, apesar de a maior parte delas trocar informações com o governo local.

\section{REFERÊNCIAS}

ANGELO, H.; HOSOKAWA, T. R.; BERGER, R. O Brasil no mercado internacional de madeiras tropicais. Revista Árvore, v.22, n.4, p.483-494, 1998.

ANSOFF, H. I. A nova estratégia empresarial. São Paulo: Atlas, 1990. 268p.

ASSIS, J. B. Base florestal de Minas Gerais. In: SEMINÁRIO DE PRODUTOS SÓLIDOS DE MADEIRA DE EUCALIPTO, (II MADETEC), 2 ., 2003, Belo Horizonte. Anais... Viçosa, MG: SIF, 2003. p.32-42.

\section{ASSOCIAÇÃO BRASILEIRA DA INDÚSTRIA DE MADEIRA PROCESSADA}

\section{MECANICAMENTE - ABIMCI. Estudo}

setorial 2003: produtos de madeira sólida. 2003. Disponível em: <http://www.abimci.com.br/ port/03Dados/0306EstSet2003/0306 Quadro.html > Acesso em: 01 abr. de 2004.
CARVALHO, R. M. M.et al. O papel do setor florestal brasileiro no contexto nacional. In: CONGRESSO FLORESTAL BRASILEIRO, 8., 2003, São Paulo. Anais... São Paulo: SBS/SBEF, 2003. v.2. CD ROM

CHIAVENATO, I. Administração nos novos tempos. 2.ed. Rio de Janeiro: Campus, 1999. 710p.

\section{INSTITUTO DE DESENVOLVIMENTO}

INDUSTRIAL DE MINAS GERAIS - INDI. A indústria moveleira em Minas Gerais. 2003. 69p. Disponível em: <http:// www.indi.mg.gov.br/publicacoes/moveleiro 2000 port.pdf>. Acesso em: 17 jul. de 2006.

NOCE, R. et al. O desempenho do Brasil nas exportações de madeira serrada. Revista Árvore, v.27, n.5, p.695-700, 2003.

NOCE, R. et al. Análise de risco e retorno do setor florestal: produtos da madeira. Revista Árvore, v.29, n.1, p.77-84, 2005.

OLIVEIRA, T. M. V. Escalas de mensuração de atitudes: Thurstone, Osgood, Stapel, Likert, Guttman, Alpert. Disponível em: <http:// www.fecap.br/adm online/art22/tania.htm $>$. Acesso em: 4 mar. 2005.

POLZL, W. B.et al. Cadeia produtiva do processamento mecânico da madeira: Segmento da madeira serrada no estado do Paraná. Disponível em: <www.tropicalcongress.com.br/portugues/ anais.html > Acesso em: 16 set., 2003.

PORTER, M. E. Vantagem competitiva: criando e sustentando um desempenho superior. Rio de Janeiro: Campus, 1992. 512p.

VALVERDE, S. R. et al. Efeitos multiplicadores da economia florestal brasileira. Revista Árvore, v.27, n.3, p.285-293, 2003. 